\title{
Entre maurofobia y maurofilia: formación e impacto del pensamiento historiográfico de Francisco Javier Simonet
}

Between maurophonia and maurofilia: formation and impact of the historigraphic thinking of Francisco Javier Simonet

\section{Isis Monserrat GUERRERO MORENO}

Universidad Autónoma Metropolitana. Unidad Azcapotzalco

Isis.unam@gmail.com

https://orcid.org/0000-0001-7766-2027

Para citar este artículo: Isis Monserrat GUERRERO MORENO (2019), "Entre maurofobia y maurofilia: formación e impacto del pensamiento historiográfico de Francisco Javier Simonet" en Revista de Estudios Internacionales Mediterráneos, 27, pp. 203-223.

Para acceder a este artículo: https://doi.org/10.15366/reim2019.27.013

\section{Resumen}

El presente texto se dirige a escudriñar las razones por las que Francisco Javier Simonet, en calidad de especialista en lengua árabe e historia andalusí, configuró una imagen ciertamente negativa y devaluada del Islam y la cultura árabe que se asentó en al-Ándalus, a pesar de que, en primera instancia, durante su juventud se distinguió como un estudiante de ideas maurófilas y, en segundo lugar, no obstante que su entorno gremial arabista se ubicó en una etapa de formación donde se apostó por una revisión histórica que permitiese reivindicar el valor de lo árabe-islámico en la historia de España.

Palabras clave: Arabismo decimonónico/ Islam / Al-Ándalus / Historiografía / Nacionalismo

\section{Abstract}

This text focuses on the reasons about why Francisco Javier Simonet, as a specialist in Arabic language and the history of al-Ándalus, configured a negative and devalued image about Islam and Arab culture that settled in al-Ándalus, being that, in the first instance, when he was young, he distinguished himself as a student with positive ideas about Islam and Arab culture and, secondly, because in his own environment, there was a profound revision that allowed to re-evaluate the Arab-islamic in the history of Spain.

Keywords: Arabism / Islam / AL-Ándalus / Historiography / Spanish Nationalism 


\section{Introducción}

En el presente artículo busco explicar por qué Francisco Javier Simonet, en calidad de especialista en lengua árabe e historia de al-Ándalus, configuró una imagen negativa y devaluada del Islam y la cultura árabe que se asentó en al-Ándalus, cuando en primera instancia, durante su juventud se distinguió como un estudiante de ideas maurófilas y, en segundo lugar, su entorno gremial arabista se ubicó en una etapa de formación donde se apostó por una revisión histórica que permitiese reivindicar el valor de lo árabe-islámico en la historia de España.

En pleno siglo XXI parecería baladí volverse a ocupar de un intelectual decimonónico que, si bien se perfiló como una de las voces académicas más autorizadas de su época, también fue un hombre que ayudó a reafirmar prejuicios y estereotipos culturales e historiográficos añejos, superados ya por investigaciones recientes; sin embargo, esgrimo que la validez del presente estudio radica en dos puntos. Primero, que las aportaciones de Simonet, polémicas dentro de su propio grupo contemporáneo de colegas arabistas, tuvieron un impacto primordial posterior, no sólo en el ámbito de la academia, sino también en los discursos políticos y educativos de las instituciones españolas del XX -pudiendo hacer esto extensivo hasta el XXI-.

Como ejemplos: la prensa de corte oficial ${ }^{1}$ durante el gobierno del dictador Francisco Franco fue un espacio donde se plasmaron algunos de los postulados del arabista con la intención de neutralizar, al interior del país, el alcance de los discursos filoarabistas divulgados internacionalmente de manera estratégica cuando el país se vio afectado por el ostracismo político que le impuso la ONU y que trató de sanearse con ayuda de algunos países árabes de reciente independencia (Álgora, 1995). Asimismo, señalar que la comprensión del pasado que representó Francisco Javier Simonet en diversos escritos fue una lectura que impregnó los contenidos de los libros escolares españoles; de tal suerte, que miles de personas se formaron una imagen histórica de al-Ándalus fundamentada en los criterios de una forma de pensamiento conservadora, fuertemente apegada a la fe católica (Rina, 2017).

Las visiones emocionales, tergiversadas que hoy podría escandalizar a los lectores críticos, no es una condición caduca, antes bien, siguen teniendo validez en múltiples espacios. ${ }^{2}$ El pasado, sus formas de comprenderlo, las estrategias para representarlo y los medios para difundirlo, son factores susceptibles para ser dirigidos por caminos tan diversos como encontrados. Puede haber una recuperación del pasado crítica, con la capacidad de tomar en cuenta la historicidad de los paradigmas y los hechos; al mismo tiempo que otra recuperación más bien nutrida por pasiones personales, intereses, prejuicios y creencias sin sustentos lo suficientemente reflexivos.

Segunda justificación: la trayectoria de Simonet opera como evidencia de que la formación elemental, aquella que se aprende en los en los primeros años de vida, suele ser influyente dentro del desarrollo posterior de los sujetos. Se verá a lo largo de este artículo que, a pesar de las enseñanzas maurófilas de Serafín Estébanez Calderón y de los descubrimientos arabistas posteriores que pudo atestiguar Simonet, su temprana formación conservadora y su fe, determinaron la interpretación histórica más acabada de su carrera. Los escritos de su madurez,

\footnotetext{
${ }^{1}$ Véanse: La Vanguardia y El ABC donde colaboraron autores como Juan Alberes, Luis Fontes de Albornoz, Adolfo Azcárraga, Tomás García Figueras, Josep Maria Millàs Vallicrosa, Eugenio d’Ors, Juan Ramón Masoliver.

${ }^{2}$ Para sustento de esta afirmación recomiendo la lectura de Rafael Sánchez Saus (2016), Al-Ándalus y la cruz. La invasión musulmana de Hispania; Serafín Fanjul (2000), Al-Ándalus contra España y, finalmente, Emilio González Ferrín (2006), Historia General de al-Ándalus. Asimismo sugiero que se sigan las polémicas surgidas a partir de dos discursos políticos: la primera suscitada por el ex presidente José María Aznar en 2004 cuando aseguró que el problema de España con al-Qaeda empezó con la "invasión de los moros" y, la segunda, más reciente de 2019, cuando el partido Vox decidió asimilarse como el heredero de la "Reconquista" que pondría en alto los valores "hispanos" en detrimento de una alteridad incómoda ¿encarnada por los musulmanes del siglo VII? (Moreno A., 2019).
} 
los que más fama alcanzaron, se vieron fuertemente calados por sus reflexiones intolerantes, antiislámicas, anti-árabes y anti-bereberes.

En esa dirección, Simonet es un ejemplo de que la comprensión histórica está sujeta al horizonte y a las condiciones de posibilidad de los individuos. Pese a los avances desarrollados por las investigaciones históricas, arqueológicas o numismáticas su perspectiva se arraigó sobre un modo de pensamiento personal, encapsulado en una restringida manera de comprender la vida, el devenir y el futuro.

A continuación, extenderé una explicación a propósito de Simonet, con base en sus aportaciones académicas, las cuales difundieron una imagen negativa de la cultura árabe-musulmana principalmente de la asentada en al-Ándalus- sino que, además, éste trató de darle fundamentos científicos a través de la Historia y la disciplina arabista moderna, de tal modo que sus ideas resultaron sumamente operativas para proyectos políticos y educativos posteriores de corte conservador (García Sanjuán, 2016).

\section{Francisco Javier Simonet: pinceladas biográficas}

\section{Aproximación de Francisco Javier Simonet a los estudios árabes e islámicos}

Francisco Javier Simonet Baca nació en Málaga el 1 de junio de 1829 en el seno de una familia entrañablemente católica. Su madre, Josefa Baca se distinguió como una mujer de costumbres conservadoras y tradicionalistas, mientras que, su padre, Antonio Simonet se caracterizó por ser un fiel creyente que en su juventud intentó seguir, aunque sin éxito, la carrera clerical. ${ }^{3}$

Como consecuencia de aquel entorno apegado a la religión y a la vida recatada, a los diez años Francisco Javier Simonet fue llevado por su padre al Seminario de Málaga incorporado a la Universidad de Granada con la intención de que el pequeño cumpliese con la vieja meta frustrada de convertirse en un siervo oficial de la Iglesia Católica. Por desgracia para el padre, tampoco tuvo la vocación suficiente para lograrlo y hacia 1845 Simonet abandonó los estudios seminaristas. En ese momento comenzó un periodo de tres años en los que frecuentó a hombres de Letras -por ejemplo su amigo Antonio Cánovas del Castillo- que lo incentivaron para salir de su ciudad natal y buscar mejores oportunidades de vida. Así, en 1848 Francisco Javier Simonet escapó de su hogar junto con su hermano Enrique y, ambos, se dieron a la tarea de llegar, como fuese, a Madrid.

Ya en la capital, el joven Cánovas del Castillo contactó a Simonet con su tío don Serafín Estébanez Calderón para ver la posibilidad de que éste le consiguiese un buen empleo; no obstante, en vista de que el propio sobrino se ocupaba de algunas labores como su secretario personal, a Simonet sólo se le pudo asignar la tarea de ordenar la biblioteca personal del afamado literato. Tal vez por verle una edad parecida a la de don Antonio su pariente o por comprender la sed de saber y trabajar digna de la juventud, don Estébanez Calderón le brindó a Simonet todo su apoyo para que pudiese mantenerse en Madrid mientras impulsaba sus planes.

El problema en dicho panorama tan alentador fue que una parte de los libros del erudito se encontraron en idiomas desconocidos por Simonet y, por ello, ordenarlos se hizo complicado.

“-Veo D. Serafín, le dijo en cierta ocasión su nuevo protegido, que sus deseos de V. son los mejores. Por este motivo, yo que no debo engañarle, le diré francamente que mi situación es muy embarazosa, al tener que clasificar obras en idiomas que no conozco, y sobre todo en lengua arábiga, en la que me parece que están multitud de volúmenes.

\footnotetext{
${ }^{3}$ Antonio Simonet perteneció a la Compañía de Jesús durante 8 años con carácter de lego.
} 
-Por esta dificultad no se apure- replicó Estébanez- Yo le enseñaré la lengua arábiga y, mientras la aprende, le daré las instrucciones apropiadas para clasificar los libros en tal idioma que poseo" (Almagro, 1904: 18).

Allende lo anecdótico de la cita, me resulta fundamental incluirla por haber sido el momento representativo en el cual Simonet se inició en el estudio de la lengua árabe. Con ello quiero puntualizar que su primera aproximación a tal campo de estudios fue más casual que intencional, pese a que en su futuro lo cultivó con esmero y lo dominó magistralmente, fue la necesidad de su primer empleo lo que le llevó a interesarse en el árabe, no así, por condiciones anteriores o por el hecho de haber crecido en una ciudad donde la influencia arábiga perduró por varios siglos.

En 1851, una vez que don Estébanez Calderón instruyó a su aprendiz con los fundamentos de la lengua árabe, lo envió a la biblioteca de El Escorial para cumplir con dos misiones. La primera, compilar información sobre la historia de la Infantería Española, mientras que, la segunda, giró en función de copiar y traducir algunos documentos árabes necesarios para sus investigaciones personales. Con eso, Simonet no sólo adquirió experiencia en materia de traducción, o conocimientos relativos a al-Ándalus, también tuvo un primer contacto con un mundo nuevo de información inédita.

Un año después se matriculó en la Universidad Central para cursar la carrera de Leyes y en 1853 comenzó su trayectoria como escritor dentro de la publicación Museo de las familias. Más aún, dados sus esfuerzos y las recomendaciones de su mentor, en 1854 obtuvo el empleo de auxiliar en las Oficinas de Correos de Madrid, con lo cual, pudo regular su precaria situación financiera.

Llegó 1857 y con él un periodo de numerosas actividades: abrió una cátedra de árabe en el Ateneo madrileño; después, se consolidó como Oficial de la Comisión Regia de Escuelas Públicas de Madrid y, en tercera instancia, inició una intensa etapa de publicaciones referentes a lengua y literatura árabe en El Occidente y La América. Vinculado a su faceta como escritor, se debe señalar que las tendencias romanticistas, orientalistas y exotistas de su tiempo lo influenciaron, de tal forma, que volcó sus esfuerzos creativos hacia la elaboración de obras relacionadas con lo oriental, lo árabe y otros elementos representativos de la imaginada vida sensualista desarrollada en alÁndalus. Las obras de autores de la talla de Washington Irving, George Byron, Walter Scott, José Zorrilla o José deEspronceda inspiraron a Simonet para reflexionar con mayor detenimiento el valor de la historia medieval hispana y hacer significativos intentos por representarla a través de mecanismos narrativos vivaces, coloridos y llenos de folclore.

Bajo esa lógica de juventud, redactó la obra titulada Leyendas árabes. Ensayos contextualizados en tierra andalusí que se propusieron representar un pasado lleno de suntuosidad, valentía y aventuras. Lejos de querer configurar un discurso científico basado en rigores documentales, el joven Simonet sencillamente quiso hacer una narración de placer donde se trenzaran fantasía y realidad (Almagro, 1904: 24-25).

En un primer momento buscó publicar dicho trabajo a través del auspicio de la Real Academia de la Historia -RAH- por lo que el texto fue canalizado hacia la censura del académico especializado Pascual de Gayangos. Éste, en calidad de crítico, afirmó que la obra no tenía el valor científico necesario por contener numerosos elementos de ficción; en su opinión, el autor debió centrarse en redactar un trabajo dirigido a esclarecer el pasado andalusí y no a tratar de recrear un panorama fantástico. Le reprochó a Simonet el haber desperdiciado gran parte de las herramientas documentales que tuvo en El Escorial al manufacturar un escrito sin dirección académica. Tras esta experiencia, el joven autor se alejó paulatinamente de los intentos por crear textos pintorescos y comenzó a trabajar sobre investigaciones de corte historiográfico, como se 
verá. Finalmente, Leyendas árabes fue publicado independientemente de la RAH en la imprenta de Juan José Martínez. ${ }^{4}$

Hacia 1858 pidió licencia para volver a El Escorial y revisar fuentes árabes de su interés que se encontraron en estado de descuido, pues, las tareas que llevó a cabo por mandato de su maestro le enseñaron que una cantidad considerable de aquel acervo necesitaba ser estudiado, traducido o, por lo menos, registrado pormenorizadamente para darle una funcionalidad operativa en el ámbito de la investigación. ${ }^{5}$

Al año siguiente no sólo logró obtener los títulos de Bachiller y Licenciado en Derecho Civil y Canónico, también se hizo acreedor al nombramiento de Caballero de la Orden de Carlos III gracias a sus funciones como comisionado para traducir varios papeles de la Corte de Marruecos. En tanto la guerra contra este país se hizo un hecho sin retorno, los intercambios entre gobiernos fueron actos ineludibles donde la cooperación arabista se volvió imprescindible.

Influencia de la guerra contra Marruecos en el pensamiento de Francisco Javier Simonet. Redescubrimiento de la Otredad musulmana

Los conflictos bélicos con el Norte África volcaron el interés social hacia los temas árabes, bereberes y musulmanes. En el contexto de la insaciable sed por querer comprender quiénes eran los enemigos a enfrentar, el arabismo y el pasado de al-Ándalus se convirtieron en protagonistas de primer orden. Simonet, consciente de que podía aprovechar tales condiciones para impulsar su propia carrera, comenzó a producir trabajos que respondiesen a las preguntas surgidas tanto en los círculos académicos como en los políticos y sociales. No obstante, conforme avanzó el conflicto y se recrudecieron las hostilidades, en su pensamiento se desarrollaron una serie de prejuicios hacia los practicantes del Islam que lo hicieron volver sobre los pasos de las valoraciones tradicionales: perfiló a los combatientes norteafricanos como sujetos violentos e irreflexivos, fanatizados por una religión falsa.

Toda la idealización del esplendoroso pasado andalusí que gestó en sus años juveniles se derrumbó progresivamente hasta convertirse en un combatiente convencido de que lo vinculado a los musulmanes no era más que mentiras surgidas de la mente de un "profeta falaz". Entonces, según su reflexión, ¿cómo un conjunto cultural con dichas deficiencias podía comprenderse como un baluarte de ciencia, esplendor o civilización? En su opinión, no había posibilidades aceptables de ello. Las propuestas de sus colegas arabistas a propósito de que los invasores del 711 habían sido los portadores de grandezas pasadas eran imprecisiones que debían ser reconsideradas y analizadas con minuciosidad. En otros términos, las posiciones conservadoras transmitidas a lo largo de los siglos adquirieron coherencia ante sus ojos $\mathrm{y}$, por ende, las lecturas revisionistas surgidas en las filas del arabismo moderno, perdieron garantía de validez.

Francisco Javier Simonet atenuó su fascinación romanticista y trató de tomar las palabras que le dedicó Pascual de Gayangos a sus Leyendas con seriedad; es decir, adoptó una posición más reacia ante las hipótesis de que los musulmanes habían atesorado grandes adelantos y saberes del mundo antiguo que transmitieron a la península ibérica. En adelante, sus investigaciones se enfocaron en "desenmascarar" aquellas entusiastas opiniones que no encontraban sustento,

\footnotetext{
${ }^{4}$ Los alcances como órgano de censura que ocupó la Academia se pueden consultar en Memorias de la Real Academia de la Historia, 1796: pp. XCVIII-CIII. Esta simbólica facultad no sufrió transformaciones en 1847 con los cambios de Estatutos.

${ }^{5}$ Tales tareas las llevó a cabo independientemente del trabajo elaborado por el padre Casiri, el cual, sin lugar a dudas, le sirvió como base para conocer una gran parte del acervo escurialense.
}

REIM № 27 (diciembre 2019) ISSN: $1887-4460$ 
según su perspectiva, a la luz de las revelaciones que exponía la experiencia bélica contra Marruecos.

El arabista Bernabé López García asegura que en la vida de Simonet hubo una ruptura interpretativa. Un antes y un después de la guerra que afectó su forma de comprender el complejo árabe-musulmán. En una primera etapa, el discípulo de don Serafín Estébanez se caracterizó por manifestar una abierta admiración por las cualidades de la literatura arábiga, así como un acentuado respeto por los grupos musulmanes que habitaron al-Ándalus; empero, tras las confrontaciones armadas, su visión se transformó hasta llegar al punto de repudiar todo lo relativo o derivado del Islam; de tal suerte, que al final de sus días, Simonet se consolidó como la personificación de la sección ultramontana del arabismo hispano moderno.

Ahora bien, con su valiosa contribución quiero convenir una reflexión. Considero que el arabista siempre mantuvo cierto escepticismo respecto de las cualidades arábigas y musulmanas; sin embargo, durante su temporada como alumno directo de don Estébanez Calderón, tales pareceres se diluyeron por dos cuestiones fundamentales. Una, por la influencia que ejerció sobre él la literatura romántica extranjera y, dos, por el ejemplo de las ideas y los trabajos elaborados por su propio mentor. En otras palabras, su visión conservadora del pasado se nubló bajo el descubrimiento de conocimientos que evidentemente no le fueron cultivados ni por sus padres ni mucho menos por los maestros del Seminario malagueño; pero, una vez "independizado" en la Universidad Central, sus cavilaciones particulares de la mano con sus experiencias políticas, le regresaron a ese estado escéptico donde la religión cristiana le resultaba la explicación justa donde se encontraban las respuestas adecuadas a propósito del origen y el desarrollo de la nación española, tal vez, incluso, de la vida humana en general.

En sus críticas palabras:

"La falsa ciencia de nuestros tiempos, al batallar contra la verdad católica, ha escojido [sic] con especial predilección el terreno de los estudios históricos, vasta el escena del humano linaje, que á todos interesa y conmueve: paisaje ameno y pintoresco que á todos deleita; campo, en fin, que con frecuencia, emboscado y oscuro, es muy á propósito para poner celadas á los entendimientos ligeros é incautos.

Lo peor del caso es que la escuela liberal, falta justamente de fe, de patriotismo y de sentido histórico, ha copiado con bajo servilismo y necia fruición los ataques más o menos injustos, á veces disparatados y ridículos, que han menudeado contra nuestra patria la absurda crítica extranjera". (Simonet, 1881: 483).

Así, las habilidades obtenidas con base en el arabismo se convirtieron en un recurso que explotó únicamente para sostener los prejuicios, conceptos e ideas que ya poseía pero que transitaron por un periodo de "hallazgos" documentales y descubrimientos de renovadas formas de representación e interpretación historiográfica al lado de su maestro. ${ }^{6}$

\section{Tiempos de madurez y proliferación académica}

Para 1862, año de mucha suerte para Simonet, acontecieron cinco gratos sucesos en su carrera: uno, ganó la cátedra de árabe en la Universidad de Granada; dos, fue nombrado miembro correspondiente de la RAH en Granada gracias al buen trabajo que hizo en su Descripción del reino de Granada; tres, se le encargó interinamente la cátedra de historia de España en la misma Universidad; cuatro, obtuvo un puesto como corresponsal de la Real Sociedad de Amigos del País de Mallorca y, finalmente, cinco, se licenció en Filosofía y Letras.

\footnotetext{
${ }^{6}$ Entiéndase por "habilidades obtenidas" el dominio de la lengua árabe, la capacidad de traducción y el acceso a las fuentes de origen árabe en repositorios públicos y privados.
} 
Los sesenta fueron años de intensas labores para el malagueño que le obligaron a seguir desarrollándose por el camino del arabismo; sin embargo, también fue una temporada donde su inclinación hacia el análisis de la historia del catolicismo en España creció y se volvió una de sus prioridades profesionales que, de hecho, no abandonó hasta su muerte.

En 1863 pidió nuevamente una licencia para visitar los acervos de El Escorial, por cuanto no sólo fue para él un sitio de riquezas documentales donde podía llenarse de necesarios armamentos para sus investigaciones, éste también se convirtió en un refugio que disfrutaba para calmar su mente y los síntomas de sus constantes achaques. Aunque para ese tiempo era un hombre joven de 34 años, su salud siempre le hostigó; durante largas temporadas le imposibilitó para ejercer su vida con normalidad. ${ }^{7}$ En numerosas cartas que le dirigió a su maestro, es posible observar sus continuas quejas a propósito de sus dolencias, aunque bien, al mismo tiempo se percibe su apasionada personalidad, caracterizada por una forma de pensamiento intolerante, arrebatada y sumamente dramática. No sólo la academia fue objeto de sus coléricas críticas, sino que a su vez, diversas personas y momentos de su vida íntima figuraron como blanco de sus extremas rabietas. ${ }^{8}$ Si algo se debe tener en cuenta es que Simonet fue un hombre quejumbroso que rayó constantemente en una personalidad irreflexivamente caprichosa. No tuvo la capacidad de mantener al margen su emocionalidad respecto de su producción académica.

El Escorial fue un sitio "de retiro" donde pudo, a decir de sus palabras, encontrar la paz imperativa para recuperar su salud y para compilar las fuentes que requirió en sus indagaciones. Piénsese que aquel lugar le resultó valioso no sólo por su biblioteca o sus archivos, también fue un monasterio donde pudo ejercer su religiosidad y rodearse de personas que compartieron su forma de comprender la vida, la muerte, la Providencia y un largo etcétera. El Escorial se perfiló como el espacio ideal para un Simonet que difería ciertamente de su tiempo; que estaba en contra de las políticas desarrolladas en su contexto por considerarlas inadecuadas, demasiado afrancesadas y liberales para mantener el orden y la dignidad de la nación española.

Pues bien, tras este lapso de retiro voluntario, en 1864 alcanzó el título de Doctor en Filosofía y Letras en Granada. Al año siguiente, se le nombró Presidente de la Sección de Ciencias Filosóficas de la Academia de Ciencias y Literatura del Liceo de Granada y, para 1866, se integró a la Comisión de Monumentos de la misma ciudad en calidad de experto traductor de la lengua árabe.

Este último año resultó altamente representativo, fue ahí cuando ganó el premio de la Real Academia de la Historia por su afamada obra Historia de los mozárabes en España. Junto con Francisco Fernández y González, Simonet participó en la convocatoria por la cual se solicitaron investigaciones que esclareciesen las condiciones de vida de los mudéjares y mozárabes de alÁndalus. Por segunda ocasión, aquellos dos maestros del arabismo se reencontraron en el ámbito académico para exponer sus perspectivas históricas respecto de un pasado que se estaba tratando de redefinir. No obstante, sus visiones opuestas, ambos se hicieron acreedores al reconocimiento público, aunque bien, fue Fernández y González el que logró publicar su obra casi de manera

\footnotetext{
${ }^{7}$ Sus síntomas más recurrentes fueron: dolores de cabeza, ojos irritados, indigestión, calenturas y dolores de pecho.

${ }^{8}$ Ejemplos de su forma enardecida de asumir la vida hay muchos, sin embargo mencionaré dos. Primero, cuando su padre hacia 1853 le envió una cantidad de dinero más simbólica que efectiva para pagar sus estudios, Simonet le dedicó una carta donde poco faltó para repudiarlo como padre; le reprochó, hasta el colmo, el ser un desconsiderado que quería matarlo de hambre allende de recriminarle el no pensar en las necesidades de su hijo. Otro ejemplo, cuando trabajó por primera vez en El Escorial por encargo de don Serafín, le envió una carta a su maestro para denunciar los malos tratos de los que era víctima por parte tanto de los bibliotecarios como de la casera que le cuidaba; empero, el arabista que ya le conocía, sólo atinó a responderle: "Haga esfuerzos sobre sí para corregir su carácter."
}

REIM № 27 (diciembre 2019) ISSN: $1887-4460$ 
inmediata. Simonet, en cambio, tuvo que esperar hasta el final del siglo para que su trabajo fuese editado y difundido.

Durante el proceso de elaboración y selección, don Serafín mantuvo estrecha comunicación con su querido amigo "Calepino" ${ }^{9}$ y, entre la información intercambiada, se animó a decirle que aunque su trabajo le parecía de gran valor historiográfico, su posición difería en buena medida de su colega Fernández y González, empero, también le aseguró que confiaba en que no habría otro ganador más que él en cuanto al tema de los mozárabes. Ahora bien, curioso fue que tras el anuncio de su victoria, también le confesó en carta fechada con el 29 de abril que:

“En cuanto a la memoria de los Muzárabes [sic] cuando se puso a votación yo opiné en que se le diese el Accésit y me quedé solo, y los que hicieron la contra fueron todos los Aljamiados ${ }^{10}$ de la Academia sin escluir [sic] a Pilatos, ${ }^{11}$ que votó con ellos sin embargo de que era su padrino. Como está acostumbrado a hacer el papel de Gabalón, como V. sabe, no lo estrañé [sic] porque el hace un cesto hace ciento" (RAH: 11/8874).

Al parecer, la decisión de la publicación dependió del consenso académico y, según se observa, el grueso de los arabistas de la época no estuvo a favor de que fuese la propuesta de Francisco Javier Simonet aquella que se editase a la brevedad. Es probable que su valoración del pasado a propósito al-Ándalus no cumpliera con las expectativas del gremio arabista encabezado por don Gayangos, por cuanto, como veremos más adelante, La Historia de los mozárabes si bien reveló información primordial sobre dicho conjunto social, también tuvo una concentración acentuada en la historia del cristianismo en la península, de tal modo, que la cuestión dogmática y la fundación de múltiples iglesias se convirtieron en los puntos centrales de la narración, deslindándose así, de los objetivos esenciales del campo de los estudios árabes (Monroe, 1970:87).

Con esta experiencia, se reafirma la idea de que Francisco Javier Simonet fue la excepción preponderante dentro de las corrientes interpretativas que se estaban formando en el seno del arabismo cultivado por la RAH y, aunque excluido en principio por esa condición, pasado el tiempo sus valoraciones se recuperaron con fines políticos y nacionalistas.

Para 1868, año convulso en el que estalló la llamada Revolución Gloriosa en España, el malagueño tomó el cargo provisional del decanato de la Facultad de Filosofía y Letras de la Universidad de Granada; contrajo nupcias con Manuela Sánchez Villanueva -miembro de una de las familias más adineradas de Granada- y, finalmente, se declaró abiertamente partidario del grupo político carlista.

En calidad de intelectual reconocido en los más encumbrados círculos sociales granadinos, comenzó una campaña de publicaciones de corte político-religioso donde se dio a la tarea de defender la restauración de la monarquía española "en toda su pureza y con todos sus prestigios" (Almagro, 1904: 40, 77). En palabra de su biógrafo y alumno Antonio Almagro:

"Simonet comenzó en esta época sus trabajos de propaganda político-religiosa, en los que manifestó siempre sus acendrados sentimientos católicos, así como su amor á las instituciones seculares de nuestra España; pues perdida la esperanza, por entonces, de la restauración de $\mathrm{D}$. Isabel, y habiendo levantado banderas de rebelión el pretendiente $\mathrm{D}$. Carlos, creyó un deber de conciencia seguir esta causa y se afilió al partido carlista" (Almagro, 1904: 41).

\footnotetext{
${ }^{9}$ Apodo afectuoso con el que se dirigía a Francisco Javier Simonet. (Almagro, 1904: 19).

${ }^{10}$ Se refiere a los pupilos de Pascual de Gayangos que eran miembros de la RAH en ese momento.

${ }^{11}$ Este sobrenombre se lo puso a Pascual de Gayangos.
} 
Es en aquel momento de su vida donde Francisco Javier Simonet se deslindó en cierta medida del campo de estudios árabes y se comprometió con la investigación histórica a propósito de la iglesia católica. En adelante, sus aportaciones se dirigieron para operar como cimientos argumentativos de las propuestas políticas ultraconservadoras del carlismo. Trató de justificar, desde las trincheras académicas, porqué el bienestar y el progreso de la población en España sólo se lograría por la unidad social bajo el estandarte de la fe y el respeto a la monarquía. Más aún, el tipo de espacios que eligió para dar a conocer sus escritos, también se deben comprender como indicadores de que sus esfuerzos se reenfocaron sobre metas más politizadas que propiamente académicas. ${ }^{12}$

Los años que siguieron no fueron fáciles para nuestro autor, puesto que las continuas levantiscas y confrontaciones civiles de las que fue testigo, le afectaron anímicamente, incluso, para realizar sus labores como catedrático en la Universidad. Un Simonet incómodo y agobiado por las incertidumbres de su entorno, radicalizó paulatinamente sus reflexiones conservadoras e impregnó sus escritos con matices de amargo proselitismo religioso (López, 2011: 140-145, 231234, 241-248).

En 1875 tuvo la oportunidad de volver a su gran refugio, El Escorial, con el objetivo de comenzar la redacción de un reporte complementario al Catálogo de Casiri. Se le consideró como uno de los académicos más familiarizados con los repositorios escurialenses para confeccionar un documento guía dedicado a los especialistas interesados en servirse de los tesoros documentales del monasterio. La visita se repitió en 1876 y luego en 1882.

Las décadas de 1870 y 1880 fueron particularmente prolíficas para Simonet en el ámbito de la escritura: en 1871 vio publicada su traducción Santoral Hispano-Mozárabe escrito por Rabí ben Zaid en 961; al siguiente año editó con mejoras y aumentos su Descripción del Reino de Granada que le hizo ganar su buena reputación en los círculos intelectuales de la Real Academia Española. Para 1880 produjo innumerables artículos para la revista La Estrella de Occidente, entre ellos: "Walada", "Málaga Sarracénica", "El judío Samuel ben Adia" y "La influencia de la civilización hispano-latina en la arábiga". Hacia 1883, publicó su destacada Crestomatía Arábigo-española que trabajó con la intención de que fuese útil en los procesos universitarios de enseñanza de la lengua árabe; dos años después, vio la luz su polémico ensayo El cardenal Ximenez de Cisneros y los manuscritos arábigo-granadinos. Y finalmente, en 1889 logró la edición tanto del Glosario de voces ibéricas y latinas usadas entre los mozárabes como de En el campo de los Mártires.

En cuanto a sus labores fuera del papel y la tinta, señalo que para 1884 no sólo tomó la vicepresidencia de la Comisión de Monumentos de la provincia, sino que, a su vez, en 1889, se le eligió como Comisario en el Reino granadino para la celebración de las fiestas del XIII Centenario de la Unidad Católica. Al iniciar la década de 1890 le hicieron decano de la Facultad de Filosofía y Letras de la Universidad granadina; empero, dicho éxito en el ámbito profesional, se vio nublado por dos acontecimientos personales: la repentina muerte de su esposa Manuela Sánchez y el abandono de su única hija, Isabel Simonet, tras tomar la decisión de convertirse en monja.

Como se podrá comprender, el fin del siglo fue difícil para Simonet. Un hombre esmerado en sus labores que tuvo una personalidad dramática se vio afectado constantemente en la escasa pasividad de su ánimo; aun así, por aquel tiempo tuvo fuerzas para publicar sus Cuadros históricos y descriptivos de Granada, así como una biografía póstuma de Reinhart Dozy; arabista extranjero que más allá de haberse distinguido como su adversario en la academia, desde 1852 se perfiló como un entrañable amigo con el que tuvo constantes intercambios epistolares.

\footnotetext{
${ }^{12}$ El Siglo Futuro fue la publicación vinculada al integrismo carlista desde donde, de manera más frecuente, combatió Francisco Javier Simonet en aquella época.
}

REIM № 27 (diciembre 2019) ISSN: $1887-4460$ 
Para 1891 imprimió su Concilio III de Toledo, base de la nacionalidad y civilización española y, además, fue elegido como representante de España en el IX Congreso Internacional de Orientalistas celebrado en Londres donde aprovechó para leer un discurso que versó sobre los orientalistas egresados de la Universidad de Granada y, también, a propósito de las condiciones sociales de las mujeres "arábigo hispanas".

Seis años transcurrieron desde aquel hecho, cuando se le notificó que la Real Academia de la Historia se encontraba interesada en publicar el trabajo que en 1866 había sido premiado; el único requisito fue que le solicitaron su presencia en Madrid para dirigir los preparativos de la edición. Sin más que perder, Francisco Javier Simonet solitario a sus 67 años accedió a trasladarse a la capital para dar los últimos toques a una investigación que, en realidad, había pulido y aumentando durante 30 años.

Apenas se instaló en Madrid, comenzó a organizar todo lo necesario para que Historia de los Mozárabes saliera a la venta sin más retrasos; empero, en vista de los inexplicables virajes del destino, tal plan quedó trunco por su sorpresiva muerte el 9 de julio de 1897. Al final, el apasionado autor nunca pudo ver publicada su más grande investigación, así como tampoco contó con la oportunidad de vislumbrar el alcance de sus postulados conservadores en la producción historiográfica de tiempos posteriores.

\section{Desarrollo del pensamiento maurófobo de Francisco Javier Simonet a través de su producción académica}

En este apartado señalaré algunas obras que Simonet creó a lo largo de su vida académica, para evidenciar el hecho de que su pensamiento siempre mantuvo un carácter maurófobo, aunque pasó por una efímera etapa "indulgente" que sólo se debió a la influencia ejercida por su maestro don Serafín Estébanez "El Solitario".

El primer conjunto de trabajos fueron aquellos que se publicaron en La América; revista fundada por Eduardo Asquerino en 1857 (López, 1971: 164). Los escritos que aportó el malagueño se fecharon desde 1858 y hasta 1863. Aunque no me ocuparé de todos sino únicamente de los más reveladores para los objetivos de esta investigación, cabe mencionar que los artículos tuvieron la particularidad de alinearse a los requerimiento principales de la propia revista; es decir, abordar temas útiles para comprender las complejas relaciones políticas establecidas entre el Norte de África y España.

Simonet decidió explicar las características de las comunidades norteafricanas con las cuales el gobierno español estaba teniendo importantes fricciones; creyó necesario unirse a las voces que apoyaron la idea de revivir el poderío imperial de una España decaída que había perdido todo su prestigio y sus fuerzas en el marco de una Europa en pleno crecimiento. Asumió la responsabilidad de justificar las acciones colonialistas que hacia 1860 se materializaron sin grandes augurios de éxito.

Por otra parte, también redactó algunos trabajos a propósito de asuntos relacionados con la cultura árabe asentada en al-Ándalus; por ejemplo, lengua, literatura, historia y arqueología. Lejos de haber sido trabajos insustanciales que sólo buscaron aumentar los caudales culturales de los lectores, dicho cúmulo de artículos respondió a la idea de que el conocimiento del pasado arábigo en la Península estaba vinculado de alguna forma a los musulmanes del Norte de África; por lo cual, los "redescubrimientos" de aquellas historias resultaban aparentemente imperativos para tratar de justificar o comprender diversos puntos de los conflictos vigentes.

Los textos de Simonet, pese a su variedad temática, no perdieron el objetivo de servir como apoyo a las intenciones expansionistas de España; más aún, nótese que no obstante el corte liberal de la 
revista, las contribuciones del autor estuvieron matizadas con un visillo conservador dirigido a aplaudir los deseos del gobierno hispano por dominar espacios extranjeros.

"Discurso sobre la importancia de los estudios árabes, pronunciados en el Ateneo científico" fue el primero de los trabajos publicados. Ahí, el joven Simonet defendió la utilidad del estudio de la lengua árabe no sólo por las posibilidades que abría su dominio para la lectura de documentación histórica, sino también, por ser una lengua viva que permitía la comunicación con un considerable número de pueblos, entre ellos, como no podía ser de otra forma: Marruecos. En sus palabras:

"Réstame, señores, manifestar que el fomentar los estudios árabes, es necesario para nosotros, los españoles, si animados de antiguos sentimientos religiosos y nacionales, queremos dar impulso a las misiones de Oriente y restablecer las de África, reivindicando los antiguos derechos que nos asisten para tener templos y casas de misión en el imperio de Marruecos; y más todavía, si con altas y grandes miras pensamos en dilatar algún día por esas comarcas, teatro de nuestras antiguas glorias, la religión del Crucificado y la dominación española" (Simonet, 1858: p. 7).

Hay dos elementos que destacar. Uno, Simonet, con tan sólo 29 años de edad y con la corta experiencia adquirida por sus labores con don Estébanez Calderón, intentó unirse a la cuadrilla de entusiastas que demandó atención, incentivos y presupuesto para el campo de estudios árabes, en tanto, ello no sólo tendría una buena repercusión sobre los adelantos científicos, también ayudaría para crear una actividad lucrativa que permitiese la manutención digna de los especialistas. Él, como otros jóvenes de su tiempo -léase Francisco Fernández y González-, se interesó en hacer notar la valía de sus conocimientos y sus posibles beneficios sociales para crear oportunidades rentables.

Dos, sin perder la cualidad de su espíritu religioso, retomó las aspiraciones del siglo XV con el objetivo de justificar una posible campaña proselitista en África donde el cristianismo fuese el medio para "civilizar" a un pueblo que, en su mente, necesitaba ayuda para desarrollarse. Por otro lado, aunque en su texto se encuentran numerosos halagos hacia la cultura árabe, cuestión exclusiva de aquella época de su vida; no por ello dejó de lado sus posiciones conservadoras generadas durante su niñez y su adolescencia en el Seminario. Su fe católica y su visión de España como nación paternal facultada para ayudar "a los menos favorecidos por la Providencia" fueron elementos preponderantes, subrayados a lo largo de su trayectoria académica.

"Sobre el carácter distintivo de la poesía árabe", "Alcázares famosos en las historias árabes" y "Edad de oro en la literatura árabe en España", más allá de sus innegables aportaciones de corte histórico, fueron artículos con un trasfondo influenciado por los problemas políticos con Marruecos. Como bien lo definió López García:

"La preocupación por lo árabe en nuestro país en estos momentos está muy vinculada a la puesta de actualidad de estos temas por la guerra de África en ciernes que, junto con los ríos de literatura que todas las publicaciones le dedicaban en el otoño de 1859, eran un buen caldo de cultivo para el desarrollo y extensión de la preocupación por la cultura árabe e hispano-musulmana" (López, 1971: 169).

El arabista en estos trabajos reconoció, por primera vez, que los prejuicios hacia "las cosas muslímicas" (Simonet, 1859: 8) entorpecieron el conocimiento sobre los acontecimientos ocurridos en al-Ándalus. De forma que no se repetirá en años futuros, recriminó que: “[...] la intolerancia de los antiguos y la indiferencia de los modernos han hecho desaparecer los más preciosos documentos de la historia nacional en el largo periodo de dominación sarracena." (Simonet, 1859: 8). Pero bien, estas palabras que no parecieran salir de un integrista, se pueden 
entender como expresiones de un periodo de gestación académica, en el cual estuvo muy presente el influjo de don Estébanez Calderón.

Con "La cuestión de Oriente", su pensamiento se aclaró, no hubo marcha atrás. En este escrito el autor demostró la afectación anímica que le causaron los problemas de los cristianos maronitas en Siria; los musulmanes se convirtieron en blanco de sus más punzantes ataques. Dejó atrás todo tipo de consideraciones históricas, religiosas y personales, para dar rienda suelta a sus percepciones más radicales e intolerantes. Exentando la importancia de la información que brindó en dicho escrito, lo que me interesa es indicar el surgimiento de su madurez como intelectual y, por ende, la independencia que comenzó a consolidar fuera de la figura de "El Solitario". En este artículo empezó a vislumbrarse el Simonet que prevaleció hasta 1897 y que se caracterizó por ser un arabista enemigo de todo lo árabe y, principalmente, de lo musulmán.

Para concluir, diré que dentro de los anteriores textos hubo ideas e información que volvió a retomar en trabajos ulteriores; sin embargo, lo que no volvió a aparecer, fue el joven Simonet admirado por las grandezas de la civilización árabe, ni tampoco, aquel que criticó a sus antecesores por no haber creado espacios adecuados para la conservación de documentos de origen árabe, o bien, por haber satanizado un pasado donde la cristiandad no fue la protagonista. En adelante, sólo se hizo presente el erudito integrista y deseoso porque España erigiese un Estado sobre los pilares de la religión y el nacionalismo conservador.

La siguiente obra en esta lista es Crestomatía arábigo-española. Este libro se hizo con la intención de engrosar el escueto arsenal de materiales disponibles en España para aprender árabe; empero, lejos de sus valiosos objetivos didácticos o de la importancia de los documentos anexados para la práctica del idioma, pretendo dirigir la mirada hacia dos puntos específicos. Primero, hacia el hecho de que la colaboración de Simonet fue con un misionero franciscano y no, por ejemplo, con algún especialista laico. No sugiero, bajo ninguna circunstancia, que por su carácter religioso el coautor, el Padre Lerchundi, no estuviese facultado para hacer una contribución al arabismo, lo que quiero destacar es el entendimiento, la empatía y la vinculación del malagueño con los hombres pertenecientes a la Iglesia. Aunque seguramente tuvo la oportunidad de trabajar con Pascual de Gayangos, José Moreno Nieto o Fernández y González, aquel prefirió emprender un plan de trabajo con un intelectual con el cual compartió sus expectativas; a saber, la idea de que el árabe podía servir para ejecutar con efectividad misiones proselitistas.

De ahí el segundo elemento sobresaliente. No conformes con los alcances académicos, Lerchundi y Simonet buscaron servir a la expansión del catolicismo tal y como le hubiese gustado a Isabel La Católica. Con armas del XIX, estos arabistas buscaron impulsar las ambiciones del XV; cualidad muy propia de una forma de pensamiento integrista, nostálgica a propósito de un pasado imperial perdido. Más todavía, con Lerchundi pudo compartir y externar la hipótesis de que los mozárabes fueron los elementos que hicieron posible el desarrollo cultural de al-Ándalus; de tal forma, que los árabes tuvieron el papel pasivo de receptores de una civilización superior a ellos y a sus tradiciones. Evidentemente dicha posición no habría tenido un futuro muy prometedor con algunos otros colegas arabistas; por cuanto, en mayor o menor medida, ellos apoyaron la teoría de que habían sido los árabes quienes llevaron a Hispania todos los saberes que impulsaron su esplendor. Pues bien, la Crestomatía me resultó interesante por estos aspectos y porque quedó como registro del proceso de desarrollo de los estudios árabes en una España atrasada frente a un Orientalismo extranjero aventajado (Simonet y Lerchundi, 1881-1883: VII).

Pasaré a la mención del Glosario de voces ibéricas y latinas usadas entre los mozárabes. Esta indagación, dedicada a Serafín Estébanez Calderón, se dirigió a demostrar dos cuestiones esenciales: primero, cómo se dio el proceso de formación del castellano y, segundo, que el latín, 
"madre de todas las lenguas que se hablan en la Península" (Simonet, 1889: 15), no había sido desplazado por el árabe entre los mozárabes; al contrario, Simonet afirmó que ellos fueron los baluartes que resistieron heroicamente la intromisión de elementos extranjeros. Aunque llegó a reconocer cierto nivel de arabización, matizó que esto fue un impacto tenue que no afectó las sólidas raíces latinas del castellano (Simonet, 1889: XXXV, XXXIX).

La propuesta que circuló por aquellos años sobre la idea de que el uso del latín se redujo a la liturgia, fue rechazada y combatida por el autor. Según aseguró: “Esta exageración, producida por la falsa ciencia del siglo pasado, que en odio a la civilización católica proclamó la supremacía de la muslímica durante el periodo de la edad media [...] encontró correctivo oportuno" (Simonet, 1889: XXXIX). Lamentó, además de lo anterior, que tales propuestas se apoyasen con "ligereza y entusiasmo juvenil" (Simonet, 1889: XLI).

¿Habrá recordado que en algún momento de sus años mozos él también se deslumbró con las cualidades del pueblo árabe y por ello consideró que sólo un entusiasmo de esa índole podría ver en la lengua semítica el golpe fatal de una influencia avasalladora? Es probable, sin embargo, en esa nueva etapa de madurez asumió la tarea de ajustar sus reflexiones para reivindicar los alcances del latín. Más aún, fue tan lejos como para asegurar que, de hecho, los mozárabes hispanizaron el árabe en tanto esta lengua se encontró fuera de su radio de dominio. Según su opinión, la distancia entre Medio Oriente y la península Ibérica, permitió que el idioma de los musulmanes sufriera cambios que lo hicieron, por decir lo menos, una lengua local. No debe pasar desapercibido que, efectivamente, mientras la expansión de los árabes ocupó territorios dominados por lenguas variopintas, se formaron diversos dialectos que se mezclaron con las raíces arábigas; no obstante, el proceso de hispanización que Simonet quiso ver en las regiones ibéricas, salió de toda proporción demostrable. Una vez más, sus cavilaciones se dejaron llevar por su amor a la cristiandad.

La obra, por otro lado, se avocó a debatir el hecho de que el pueblo invasor trajo consigo un caudal significativo de conocimientos. A partir de sus pesquisas, el arabista declaró que habían sido los mozárabes los que se encargaron de aprovechar los materiales que llegaron por conducto de los árabes. En otras palabras, ellos fueron los encargados de traducir, explicar y divulgar los saberes que no habían sido lo suficientemente procesados por los hombres de Oriente. Volvió sobre lo mismo: los musulmanes, en calidad de pueblo fundamentalmente bélico, no contó con la capacidad para aprovechar y transmitir lo que compiló de los diversos pueblos que conquistó; tuvieron que llegar a Hispania para que las semillas dieran los frutos que hoy conocemos. En términos de Simonet, los indígenas cristianos operaron como la tierra abonada que posibilitó el florecimiento de al-Ándalus (Simonet, 1889: LIV).

Desde una lectura filológica y lingüística, este Glosario expuso que, aunque distorsionados, tanto el castellano como el latín fueron la evidencia del alto nivel cultural de los mozárabes y, a su vez, de la resistencia que estos últimos opusieron para conservar su "nación". En términos precisos, la aportación de Simonet dio a conocer, qué hablaron los mozárabes, cómo se formó la lengua castellana, qué influencias mínimas árabes tuvo a lo largo de su formación y, finalmente, por qué ellos fueron los bastiones de la cultura y los adelantos científicos de la Edad Media. Parece que el combativo malagueño aprovechó el espacio para externar su posición respecto de la comunidad musulmana medieval. Su empeño por acentuar el valor del "pueblo indígena", le llevó a querer demostrar que la compleja realidad histórica de aquel periodo se redujo a diferencias sociales en materia religiosa. En sus reflexiones, el mundo andalusí estuvo dividido en una sencilla estructura maniquea entre "buenos y malos"; cristianos e "infieles"; hombres libres "adoradores de su patria" y "bárbaros invasores sin escrúpulos". 
El siguiente escrito del que me ocuparé se tituló "Caída del reino visigodo y conquista de España por los sarracenos". Ésta fue una investigación que apareció publicada por partes en El siglo futuro diario católico, a lo largo del mes de octubre de 1893. Aquí, con base en la historia del cristianismo peninsular, el autor relató el proceso de conquista musulmana que inició en el 711. Ahora bien, este escrito que pareciera en primera instancia servir para brindar información histórica, lo comprendo más como una exhortación a los lectores para que notasen que su entorno político dividido e influenciado por un liberalismo interesado en deslindar a la Iglesia de los asuntos del Estado, era muy similar a las condiciones vividas en Hispania antes de la invasión. Y no sólo eso, da la impresión de que el autor extendió una invitación para terminar con dichas circunstancias y volver sobre la guía brindada por el catolicismo; pues, de lo contrario, el futuro de la nación estaba comprometido y en riesgo de sufrir una catástrofe igual a la padecida en el siglo VIII. El historiador no vaciló en comparar a los invasores musulmanes con los liberales afrancesados del XIX, ni en destacar que la reivindicación era posible como se había demostrado en 1808 cuando el pueblo español peleó y venció a las fuerzas napoleónicas.

El conjunto de artículos resulta fundamental por cuanto permiten ver con claridad que Simonet fusionó su fase como investigador con sus convicciones políticas y proselitistas. Lejos de hacer una aportación por y para la academia, se inclinó hacia la difusión en un sentido combativo, dispuesto a colaborar con la facción carlista en su misión de retomar la popularidad social y el mando.

Con esto quiero mostrar la distancia que, en su madurez intelectual, el autor acentuó respecto del arabismo moderno para volcarse hacia una práctica historiográfica útil para fines religiosos y políticos. Fue una etapa que no considero que surgió de forma espontánea e inexplicable desde la década de los sesenta; estimo que fue un punto al que se llegó de manera natural por su temprana formación, por la ineludible influencia de la educación que le dieron sus padres, por su exacerbado temperamento $y$, finalmente, por las experiencias políticas que le rodearon, especialmente el problema con Marruecos.

Quiero concluir este apartado con la mención de la obra cumbre surgida de las manos de Simonet: Historia de los mozárabes de España. Como adelanté, este trabajo se presentó en 1866 a raíz de la convocatoria lanzada por la RAH; empero, pese a que ganó el premio correspondiente a su categoría, no se publicó sino hasta 1897, poco tiempo después del fallecimiento del autor.

Podría reclamarse que el producto final estuvo distorsionado en vista de que no fue el autor original quien le dio los toques últimos, pero considero que fuera de algunos detalles menores, Simonet tuvo la oportunidad de asentar sus objetivos primordiales en aquellas páginas. Piénsese que no se trató de un escrito presentado y olvidado entre los anaqueles de un librero personal; Historia de los mozárabes fue el fruto de 30 años de trabajo constante. El autor se dedicó a alimentar, ensayar y reescribir el proyecto que le ayudó a granjearse el respeto de los eruditos de la Academia. ${ }^{13}$

Para comenzar. Mencionar que el libro dividido en dos tomos se constituyó de un prólogo, cuatro capítulos principales y un agregado de apéndices que, en su conjunto, adoptaron el objetivo de: "[...] escribir la historia de aquellos españoles que, subyugados por la morisma [...] conservaron constantemente por espacio de muchos siglos la religión, el espíritu nacional y la cultura de la antigua España romano-visigótica y cristiana [...]." (Simonet, 1897-1907: XV). Y Simonet no vaciló, su narración no dejó fuera un solo aspecto de la vida de los mozárabes. En primer lugar, presentó un ensayo basado en la filología y la etimología sobre las denominaciones que a lo largo de la

\footnotetext{
13 “En 1885 fue autorizado por Real Órden para trasladarse a Madrid para llevar a cabo la impresión de su obra; sin embargo, no lo hizo, pasaron 11 años para que lo tomara, en 1896, pero murió el 9 de julio de 1897. La misión inconclusa quedó en manos del joven Manuel Gómez Moreno [...]" (López, 2001: 16).
} 
historia se usaron para designar a los que él indicó como mozárabes. Con base en un recuento documental, tejió un argumento que dio a conocer los conceptos árabes y latinos que los lectores podían encontrar y relacionar con tal grupo social.

Posteriormente, expuso un estado de la cuestión sobre la temática, demostrando con ello su alto nivel de erudición; pero más aún, comenzó a introducir las características básicas de las comunidades mozárabes; es decir, lenguas que hablaron -árabe y romance-, la religión que practicaron, su estatus jurídico ante el dominio musulmán y algunas de sus costumbres sociales que los distinguieron de sus contemporáneos. Asimismo, en esta sección brindó el panorama histórico que provocó el surgimiento de tales comunidades; desarrolló la historia de la invasión y la conquista árabe desde el 711; no obstante, el foco de su narración fue tanto el origen como el desenvolvimiento mozárabe que logró la sobrevivencia del cristianismo en los pueblos controlados por el Islam.

A diferencia de otros arabistas e historiadores que se ocuparon de tales paradigmas, Simonet incluyó en su relato los asuntos dogmáticos que revistieron la fe de los mozárabes. Sin escatimar en tinta, detalló cuáles fueron sus elementos principales y por qué se diferenciaron, durante muchos años, del catolicismo practicado en Roma. Como buen aprendiz del Seminario, supo que la historia no podía estar completa sin mencionar las cualidades internas de lo que fue el cristianismo de al-Ándalus, pues dadas sus condiciones especiales, fue una forma de religión particular.

En adelante, la obra, aunque no perdió de vista los sucesos acontecidos con los grupos musulmanes, se tornó en una investigación dedicada a esclarecer el desenvolvimiento y los avatares que la Iglesia sufrió por la inestabilidad de las condiciones políticas. Me refiero a que el autor se consagró a explicar, por ejemplo, qué recintos sagrados se destruyeron, se construyeron, se compartieron con los musulmanes -léase la Mezquita de Córdoba- o se tuvieron que cambiar de locación por mandato expreso de las autoridades. Señaló los cambios en la legislación musulmana que afectó directamente al cristianismo en sus prácticas, permisos y restricciones; agregó múltiples biografías de mártires y santos que se perfilaron como héroes del grupo social subyugado; y, además, dedicó buena parte de su narración para indicar el origen y el domicilio de las reliquias sagradas que se consideraron como fragmentos de una memoria religiosa anterior a la invasión. Cabe mencionar que para el autor, la escritura de la historia del periodo andalusí, sirvió para poner en evidencia que "la patria española" sobrevivió a una embestida desafortunada gracias al cristianismo y a los hombres que no abandonaron sus convicciones ante un grupo bélico por excelencia.

Allende la gran la cantidad de datos que se pueden encontrar en este material, quiero hacer cinco observaciones. Primero, que en su relación histórica, Simonet subrayó los hechos que estimó como angulares para que la cristiandad triunfase sobre los musulmanes; a saber, la guerra que ganó Pelayo en Covadonga, la aparición ibn Hafsún como rebelde que puso en jaque el orden islámico, la toma de Toledo por parte de Alfonso VI y la alianza matrimonial entre Isabel y Fernando el Católico. De ello, lo importante es que los elementos de dicha selección, en tiempos ulteriores, se convirtieron en hitos fundacionales de la nación española. No fueron acontecimientos simples de un relato, adquirieron el valor de puntos claves que la memoria colectiva y la historiografía de corte oficial conservaron para sustentar el origen de una identidad nacional colectiva. Si bien no fue el primer autor en hacerlos notar, su escrito ayudó en la consolidación de ellos como partes constitutivas de un discurso politizado.

En segunda instancia, la obra le dio un segundo aire a la visión del pasado bajo la que se satanizó el dominio musulmán. Todo aquello que sus colegas trataron de matizar o destruir por completo, 
él lo reanimó a través de una forma de comprensión del pasado maniquea. La realidad andalusí la redujo a una guerra santa entre cristianos y practicantes del Islam, no quedó, aparentemente, más alternativa que regresar a los postulados tradicionales de antes del siglo XVIII, tal vez, con la única diferencia de que Simonet intentó consolidarlos bajo los criterios de las nuevas formas de hacer historia, es decir, con estrictos sustentos documentales y científicos.

Mi tercera observación es que el autor le adjudicó a la historia la función clásica de "maestra de vida", en tanto, el ejemplo de los ancestros debía recuperarse y reflexionarse para corregir el presente. No debe quedar duda de que su pensamiento fue una consecuencia directa de sus disconformidades políticas con el liberalismo; de hecho, es probable que ante su incapacidad por ejercer una acción más directa en su entorno, la producción histórica se convirtiese en el único recurso que le quedó para tomar una participación evidente y exponer sus juicios personales.

Cuatro. Para el arabista la historia de España ${ }^{14}$ fue equivalente a la historia de la Iglesia católica peninsular con todo y sus particularidades. Sus escritos manifestaron que no concibió una división entre ambos, puesto que el cristianismo era la esencia y el fundamento de ese ente atemporal que invistió a la península Ibérica; es decir, España. Los diferentes pueblos que llegaron a asentarse en la región fueron accidentes que tuvieron sentido únicamente por ser parte de un plan Providencial que llevó por meta definir el rostro de la nación española. En otras palabras, la llegada de la fe cristiana fue el acta de nacimiento indiscutible del objeto de estudio que ocupó casi toda su vida: España.

Finalmente, el quinto aspecto es que Historia de los mozárabes en España fue la síntesis de todo el pensamiento y toda la producción que Simonet realizó en su vida. Cada una de las ideas que analizó, que defendió o que atacó, quedaron plasmadas en su más extensa investigación. Fragmentos completos que redactó para otras narraciones, se pueden encontrar en este último libro que legó a la posteridad y que, paradójicamente, tras varios obstáculos en su trayectoria, vio la luz cuando el autor no pudo combatir más con la tinta y el papel.

\section{Conclusiones}

Para cerrar el presente artículo quiero enumerar las conclusiones más representativas. Uno, la formación académica de juventud y la influencia de las costumbres familiares impactaron en el desarrollo del pensamiento maurófobo de Simonet; sin embargo, no pretendo que estas condiciones se consideren deterministas, mi propuesta radica en adicionar tales elementos a otros factores ya conocidos que también contribuyeron en la formación de sus criterios; por ejemplo, sus experiencias políticas, los conocimientos que adquirió ante los conflictos en Siria y Marruecos; sus vivencias dentro de los ajetreos sociales hispanos de la segunda mitad deI XIX, etcétera. Lo que aquí se ofreció fue una perspectiva que buscó ampliar el conocimiento a propósito de uno de los autores más importantes del arabismo, allende de centrar la atención sobre un punto que en ocasiones es desvalorizado por los investigadores; esto es, el ámbito personal.

Dos, pese a que se podría considerar que Simonet fue un autor perteneciente al gremio de los historiadores del cristianismo hispano, resulta fundamental observarlo desde el arabismo, por cuanto fue el espacio disciplinar que durante el XIX adoptó la explícita misión de hacer un revisionismo crítico respecto de la producción historiográfica versada sobre al-Ándalus. Entonces, en vista de que él se formó como investigador en el seno de dicho campo de estudios, resultó representativo observar la ruptura que encarnó por sus valoraciones historiográficas. Con ello se demuestra la versatilidad de los procesos de creación de conocimientos dentro del arabismo que

\footnotetext{
${ }^{14}$ Entiéndase España como un ente atemporal y omnipresente.
} 
buscaron no sólo información sino también nuevas formas de comprender el pasado y el presente de la nación en formación.

Tres, ante el rechazo que Simonet profesó por el Islam, sus estrategias de representación histórica se enfocaron en deslindar toda posible relación entre los elementos culturales y religiosos de 10 árabe y lo musulmán por medio de una estrategia de hispanización. Aquello que evaluó como provechoso de los Otros lo explicó como una ineludible consecuencia del contacto directo que se tuvo con lo indígena, mientras que, rechazó lo que calibró como inapropiado o incompatible con el espíritu cristiano. En otros términos, recurrió a la estrategia de familiarización cuando percibió que dentro de la alteridad había características que beneficiaban a la identidad nacional de España, cuando, por otra parte, acentuó la extranjerización de todo lo demás que le resultó inútil o inadecuado. (Gil Bardají, 2008). ${ }^{15}$

Cuatro. Destacar que pese a ser un intelectual ciertamente marginado del grupo de investigadores arabistas de su tiempo, sus ideas tuvieron una trascendencia singular dentro del sistema educativo y de los discursos identitarios del nacionalismo católico conservador que se desarrollaron hacia los siglos XX y XXI (Guerrero, 2012). Explico, aunque la conveniencia política internacional de Francisco Franco apuntó a difundir una imagen amable y familiar de lo árabe gracias al momento que se compartió en al-Ándalus y al ostracismo impuesto por la ONU tras la Segunda Guerra Mundial; en el interior del país la prensa -uno de los medios de comunicación más importantes- se dedicó a reafirmar la supremacía cristiana -cultural e ideológica- que permitió el progreso de la nación. En ese sentido, se retomaron los postulados de Simonet que versaron sobre la inferioridad de lo árabe, así como la importancia de la religión católica como factor primordial de impulso y unificación social en España.

En cuando a la educación, será suficiente hacer notar que el perfil de los currículums escolares se guió por la obra de Modesto Lafuente Historia General de España que, sin lugar a dudas, coincidió en valoraciones en cuanto a la historia andalusí con Francisco Javier Simonet. En consecuencia, durante numerosos años, al-Ándalus, en un amplio nivel social, se comprendió bajo parámetros maniqueos y simplistas que, de hecho, hoy siguen invistiendo diversos discursos políticos (Maestro González, 2002). ${ }^{16}$

\section{Bibliografía}

ALMAGRO Cárdenas, Antonio (1904): Biografía del doctor D. Francisco Javier Simonet, Granada, Tip. Lit. de Paulino Ventura.

ÁLGORA Weber, María Dolores (1995): Las relaciones hispano-árabes durante el régimen de Franco: la ruptura del aislamiento internacional (1946-1950), Madrid, Ministerio de Asuntos Exteriores.

EL-MADKOURI Maataoui, Mohamed: “España y el mundo árabe: imagen e imaginario", TONOS. Revista electrónica de Estudios Filológicos, 2004, disponible en: https://www.um.es/tonosdigital/znum7/portada/tritonos/Imagendeespahtm.htm [consulta: 5 de febrero de 2016].

ESTÉBANEZ Calderón, Serafín, "Carta de 'El Solitario' a Simonet con fecha de 1851", en Documentos referentes a Estébanez Calderón, Dozy, Simonet y a Granada, donados por D. Manuel

\footnotetext{
${ }^{15}$ Sus escritos se encargaron de clarificar las diferencias entre los variopintos grupos sociales para que los lectores no tuviesen dudas sobre quiénes eran hispanos o españoles y quiénes eran sólo sujetos transitorios en el devenir de la patria. Sin menos cabo, para el arabista la identidad española se definió por la fe y la raza, no así por un derecho histórico, político o por una asimilación personal.

${ }^{16}$ Véase la nota 2 de este artículo.
} 
Gómez Moreno... en 30 de octubre de 1962, [signatura: 11/8874] Biblioteca General de la Real Academia de la Historia, Madrid.

GARCÍA, Luis (11 de octubre de 1896): "El Dr. Francisco Javier Simonet y Baca", La Unión Escolar granadina. Semanario independiente, de asuntos escolares, $\mathrm{n}^{\circ} 2, \mathrm{p} .4$.

GARCÍA Sanjuán, Alejandro (2018): "La creciente difusión de un fraude historiográfico: la negación de la conquista musulmana de la península ibérica", Vínculos de Historia, n7, pp.173-193.

GARCÍA Sanjuán, Alejandro (julio-diciembre de 2016): "La persistencia del discurso nacionalcatólico sobre el Medievo peninsular en la historiografía española actual", Historiografías, n¹2, pp. 132-153. https://doi.org/10.26754/ojs historiografias/hrht.2016122367

GIL Bardají (2008): Traducir al-Ándalus: El Discurso del otro en el arabismo español [de Conde a García Gómez] (Tesis de Doctorado), Departamento de Traducción e Interpretación Universidad de Barcelona, Barcelona.

GÓMEZ Moreno, Manuel (MCMLXII): Dozy et Simonet. Extrait des Etudes d'Orientalisme dédiées à la mémoire de Lévi-Provencal, Paris, G.P.Maisonneuve et Larose.

GÓMEZ Moreno, Manuel (1953): “Unas cartas de El Solitario", Boletín de la Real Academia Española, t. 33, pp.209-242.

GUERRERO Moreno, Isis Monserrat (2012): Las relaciones político-culturales entre el franquismo y el islam a través de la prensa escrita durante la posguerra, 1945-1955 (Tesis de Licenciatura), Facultad de Filosofía y Letras, Universidad Nacional Autónoma de México, México.

HERNANDO de Larramendi Martínez, Miguel (2014): "Las relaciones exteriores de España con el mundo árabe y musulmán durante el siglo XX", Awraq: Estudios sobre el mundo árabe e islámico contemporáneo, $\mathrm{n}^{\circ} 9$, pp. 39-54.

HERNANDO de Larramendi Martínez, Miguel y Bernabé López eds. (2010): España, el Mediterráneo y el mundo arabomusulmán. Diplomacia e Historia, Barcelona, Icaria: Instituto Europeo del Mediterráneo (IEMed).

LÓPEZ García, Bernabé (1971): “F.J. Simonet ante el colonialismo (1859-1863): Unos artículos en La América", Cuadernos de Historia del Islam, 1 serie miscelánea.

LÓPEZ García, Bernabé (1990):“Arabismo y Orientalismo en España: radiografía y diagnóstico de un gremio escaso y apartadizo", Awraq: Estudios sobre el mundo árabe e islámico contemporáneo, (Ejemplar dedicado a: Africanismo y Orientalismo Español), nextra 1, pp.35-69.

LÓPEZ García, Bernabé (2001): “Origen, gestión y divulgación de la 'Historia de los Mozárabes' de Francisco Javier Simonet (con una bibliografía del Simonet publicista)", Awraq: Estudios sobre el mundo árabe e islámico contemporáneo, $\mathrm{n}^{\circ} 22$.

LÓPEZ García, Bernabé (2011): Orientalismo e ideología colonial en el arabismo español (18401917), Granada, Universidad de Granada.

LÓPEZ García, Bernabé: "El arabismo español de fines del XIX en el debate historiográfico y africanista", ACADEMIA.EDU, 2014, disponible en: https://www.academia.edu/24556 [consulta: 16 de agosto de 2017].

MAESTRO González, Pilar: "El modelo de las historias generales y la enseñanza de la historia", Actas del VI Congreso de la Asociación de Historia Contemporánea "Usos públicos de la Historia", 2002, disponible

https://ojs.uv.es/index.php/dces/article/view/2906/2478?fbclid=IwAR39OiWBXCKXnzIXWhTO43iZ 39x8zHj19okB9caYFixPP-ECH-PB8jI0XoE

MANZANARES de Cirre, Manuela (1972): Arabistas españoles del siglo XIX, Madrid, Instituto Hispano-Árabe de Cultura.

MANZANO Moreno, Eduardo (2000): "La creación de un esencialismo: la historia de al-Ándalus en la visión del arabismo español" en, FERNÁNDEZ Parrilla, Gonzalo y Manuel Ferias (coords.): 
Orientalismo, exotismo y traducción, Castilla-La Mancha, Ediciones de la Universidad de Castilla-La Mancha, pp. 23-37.

MARín, Manuela (1992): "Arabistas en España: un asunto de familia", Al-Qantara, n², pp. 379394.

MARíN, Manuela "et al". (2009): Al-Andalus/España. Historiografías en contraste Siglos XVII-XXI, Madrid, Casa de Velázquez.

MARTínEZ Montávez, Pedro (2011): Significado y símbolo de Al-Ándalus, Almería, Fundación Ibn Tufayl de Estudios Árabes.

MONROE, James T. (1970): Islam and the Arabs in Spanish Scholarship: Sixteenth Century to the Present, Leiden, E.J. Brill.

MORALES Lezcano, Víctor (1990): Africanismo y orientalismo español en el siglo XIX, Madrid, ICMA. MORENO, A.: “¿Por qué Vox rescata ahora el viejo concepto de 'Reconquista'?”, Público, 15 de enero de 2019, disponible en https://www.publico.es/politica/ultraderecha-vox-rescata-viejoconcepto-reconquista.html [consulta 20 de febrero de 2019].

RINA, César (enero del 2013): "Discursos de alteridad en las Historias Generales de España. La invasión musulmana y la conquista de Granada. 1840-1890", Revista de Historiografía, n¹8, pp. 124-132.

RINA, César: "La didáctica de la Historia en los procesos de nacionalización. Trayectoria, constantes y propuestas", CLIO. History and History teaching, 2017, disponible en: https://unex.academia.edu/C\%C3\%A9sarRina [consulta: 15 de febrero de 2019].

RíOS Saloma, Martín (2011): La Reconquista. Una construcción historiográfica (siglos XVI-XIX), Madrid: México, UNAM: IIH: Marcial Pons Historia.

RIVIÉRÈ Gómez, Aurora (2000): Orientalismo y nacionalismo español: Estudios árabes y hebreos en la Universidad de Madrid (1843-1868), Madrid, Libros Dykinson.

SIMONET, Francisco Javier, "Carta de Simonet a Estébanez Calderón con fecha de julio de 1853" en, Documentos referentes a Estébanez Calderón, Dozy, Simonet y a Granada, donados por D. Manuel Gómez Moreno... en 30 de octubre de 1962, [signatura: 11/8874] Biblioteca General de la Real Academia de la Historia, Madrid.

SIMONET, Francisco Javier, "Carta de Simonet a Manuel con fecha del 30 de diciembre de 1854", Documentos referentes a Estébanez Calderón, Dozy, Simonet y a Granada, donados por D. Manuel Gómez Moreno... en 30 de octubre de 1962, [signatura: 11/8874] Biblioteca General de la Real Academia de la Historia, Madrid.

SIMONET, Francisco Javier (8 de diciembre de 1858): "Discurso sobre la importancia de los estudios árabes, pronunciados en el Ateneo científico en diciembre de 1858”, La América, n¹9, pp. 5-7.

SIMONET, Francisco Javier (24 de diciembre de 1858): "Discurso sobre la importancia de los estudios árabes, pronunciados en el Ateneo científico en diciembre de 1858", La América, n²0, pp. 6-7.

SIMONET, Francisco Javier (8 de noviembre de 1859): "La empresa de África", La América, n¹7, pp. 8-9.

SIMONET, Francisco Javier (8 de diciembre de 1859): "De la civilización africana", La América, $\mathrm{n}^{\circ}$ 19, p.2.

SIMONET, Francisco Javier (24 de diciembre de 1859): "De la civilización africana", La América, $\mathrm{n}^{\circ} 20$, pp. 2-4.

SIMONET, Francisco Javier (8 de marzo de 1859): "Sobre el carácter distintivo de la poesía árabe", La América, $\mathrm{n}^{\circ} 1$, pp.8-9.

SIMONET, Francisco Javier (24 de mayo de 1859): "Alcázares famosos en las historias árabes", $L a$ América, $\mathrm{n}^{\circ} 6, \mathrm{pp} .7-8$. 
SIMONET, Francisco Javier (24 de junio de 1859): "Alcázares famosos en las historias árabes", La América, $\mathrm{n}^{\circ} 8, \mathrm{pp} .12-14$.

SIMONET, Francisco Javier (8 de julio de 1859): "Alcázares famosos en las historias árabes", La América, $\mathrm{n}^{\circ} 9$, pp.8-9.

SIMONET, Francisco Javier (24 de septiembre de 1859): "Edad de oro en la literatura árabe en España", La América, n¹4, pp.8-9.

SIMONET, Francisco Javier (8 de octubre de 1859): "Edad de oro en la literatura árabe en España", La América, n¹5, pp. 11-12.

SIMONET, Francisco Javier (8 de diciembre de 1859): "La cuestión de Oriente", La América, n¹9, pp.2-3.

SIMONET, Francisco Javier (24 de febrero de 1860): "Del derecho de guerra y conquista", La América, n¹9, pp. 3-4.

SIMONET, Francisco Javier (8 de marzo de 1860): "La conquista de Tetuán", La América, n¹9, pp.3-4.

SIMONET, Francisco Javier (1860): Descripción del reino de Granada bajo la dominación de los naseritas: sacada de los autores árabes y seguida del texto inédito de Mohammed ebn Aljatib, Madrid, Imprenta Nacional.

SIMONET, Francisco Javier (8 de febrero de 1861): "Iliberis y Granada", La América, n²3, pp. 1011.

SIMONET, Francisco Javier (24 de marzo de 1861): "Descripción de Ceuta bajo la dominación árabe", La América, n², p.13.

SIMONET, Francisco Javier (24 de julio de 1861): "Descripción de la ciudad de Málaga bajo la dominación árabe", La América, n¹0, pp.12-13.

SIMONET, Francisco Javier (1866): Discursos leídos ante el claustro de la Universidad Literaria de Granada en el acto solemne de la recepción del Lic. D. Francisco Javier Simonet como catedrático numerario de la lengua árabe en la Facultad de Filosofía y Letras el 15 de septiembre de 1862, Granada, Imprenta y librería de D. José M. Zamora.

SIMONET, Francisco Javier: Santoral hispano-mozárabe escrito en 961, 1871, disponible en: http://www.cervantesvirtual.com/obra/santoral-hispano-mozarabe/ [consulta: 4 de agosto de 2017]

SIMONET, Francisco Javier (1872): Descripción del reino de Granada, sacada de los autores arábigos, Granada, Imprenta de Reyes y hermano.

SIMONET, Francisco Javier (31 de julio de 1881): "Crítica histórica", La revista católica. Semanario de ciencias eclesiásticas y literatura religiosa dedicado a su santidad el papa León XIII, $\mathrm{n}^{\circ}$ 192, p. 483.

SIMONET, Francisco Javier y José Lerchundi (1881-1883): Crestomatía arábigo-española, Granada, Imprenta de Indalecio Ventura.

SIMONET, Francisco Javier (1885): El cardenal Ximenez de Cisneros y los manuscritos arábigogranadinos, Granada, Imprenta de La Lealtad.

SIMONET, Francisco Javier (1889): Glosario de voces ibéricas y latinas usadas entre los mozárabes, precedido de un estudio sobre el dialecto hispano-mozárabe, obra premiada en público certamen de la Real Academia Española y publicada a sus expensas, Madrid, Establecimiento tipográfico de Fortanet.

SIMONET, Francisco Javier (1889): "En el campo de los Mártires", Boletín del Centro Artístico de Granada, Granada.

SIMONET, Francisco Javier (1890): Cuadros históricos y descriptivos de Granada, Granada, Imprenta de Guevara. 
SIMONET, Francisco Javier (30 de noviembre de 1890): "Biografía de Reinhart Dozy", Boletín del Centro Artístico de Granada, n $^{\circ} 2$.

SIMONET, Francisco Javier (1891): El Concilio III de Toledo, base de la nacionalidad y civilización española, edición políglota y peninsular en latín, vascuence, árabe, castellano, catalán, gallego y portugués, precedida de un prólogo de Francisco J. Simonet y de un estudio histórico por el P. Juan Antonio Zugasti, Madrid, Imprenta de Fortanet.

SIMONET, Francisco Javier (1891): Memoria presentada en el IX Congreso Internacional de Orientalistas celebrado en Londres en septiembre de 1891, Granada, Imprenta de D. José López Guevara.

SIMONET, Francisco Javier (14 de octubre de 1893): "Caída del reino visigodo y conquista de España por los sarracenos", El siglo futuro, diario católico, n5598, p.1.

SIMONET, Francisco Javier (1897-1903): Historia de los mozárabes de España deducida de los mejores y más auténticos testimonios de los escritores cristianos y árabes. Obra premiada en público certamen de la Real Academia de la Historia y publicada a sus expensas, Madrid, Establecimiento tipográfico de la viuda e hijos de M. Tello.

SIMONET, Francisco Javier: Expediente personal, Archivo de la Faculta de Filosofía y Letras de la Universidad de Granada, signatura: ES AUG PRINCIPAL CAJA 00667/130. 